ORIGINAL ARTICLE

\title{
Point-of-sale glass bottle recycling: indoor airborne exposures and symptoms among employees
}

\author{
S M Kennedy, R Copes, K H Bartlett, M Brauer
}

Occup Environ Med 2004;61:628-635. doi: 10.1136/oem.2003.009753

See end of article for authors' affiliations

. n......

Correspondence to: Prof. SM Kennedy, School of Occupational and Environmental Hygiene, University of British Columbia, 2206 East Mall, Vancouver BC, V6T 1Z3, Canada; kennedy@ interchange.ubc.ca

Accepted 29 January 2004
Aims: To assess the impact of newly introduced point-of-sale glass bottle recycling on indoor air quality and employee health.

Methods: Airborne exposures and both chronic and acute respiratory and somatic symptoms were surveyed among 226 employees at 36 randomly selected liquor stores with bottle recycling and in-house glass breaking. Each store was visited twice; between visits glass breaking was discontinued for one month in half the stores (selected at random), although bottles were still collected and stored on site. Rates of chronic symptoms were compared to an external, unexposed control population.

Results: Geometric mean exposure levels were $0.18 \mathrm{mg} / \mathrm{m}^{3}$ for inhalable particulate matter and $3.6 \mathrm{EU} /$ $\mathrm{m}^{3}$ for endotoxin (270 personal samples); $1064 \mathrm{CFU} / \mathrm{m}^{3}$ for viable fungi (648 area samples). Fungal levels were associated with visibly mouldy bottles being broken, outdoor fungal counts, and uncovered glass bins. Exposures were not altered by the intervention of shutting down glass breaking machinery. Compared to controls, employees reported more work related chronic chest tightness and chronic nasal symptoms. Acute chest symptoms were associated with breaking visibly mouldy bottles, but not with measured fungal counts. Inhalable particulate matter levels $>0.2 \mathrm{mg} / \mathrm{m}^{3}$ were associated with acute upper airway irritation. Somatic symptoms were associated with measures of psychosocial job strain.

Conclusion: Results suggest that this type of recycling programme may generate fungal exposures sufficient to elicit upper airway and chest symptoms.
$\mathrm{P}$ oint-of-sale recycling refers to the practice of returning recyclable materials to the store where the item was purchased. Although such programmes can have a positive impact on environmental pollution, their impact on indoor air quality and employee health is unknown.

In British Columbia (BC), Canada, liquor store customers are encouraged to return all glass bottles for a refund. As part of a recycling programme, glass breaking equipment was recently installed in the bottle return area of each store. Employees feed the bottles into a glass breaking machine placed over a collecting bin. Broken glass accumulates in the bin and employees use a rake to level the broken glass to prevent the pile from backing up into the breaker. When the equipment is operating, the bin is covered and exhausted to local dust collecting system. When the bin is full, employees remove the cover and replace the full bin with an empty one.

Since the installation of the machines, employees have complained of mucous membrane irritation and bleeding, respiratory irritation and breathlessness, and skin rashes. A literature search revealed no information about potential health impact of such local glass recycling activities. We believe ours is the first such report. Domestic recycling of other products has been associated with respiratory symptoms and acute reductions in lung function among workers at recycling facilities. ${ }^{12}$ Our objective was to assess the health impact of the airborne exposures associated with this recycling operation. We measured airborne concentrations of inhalable particulate matter (IPM), viable moulds, and endotoxin in these stores and assessed exposure-response relations between these pollutants and acute and chronic respiratory symptoms.

\section{METHODS}

Study design and population

A stratified random sample of 36 stores was selected from the 223 government liquor stores in BC (stratification by region).
Each store was visited twice and all full time employees present on each testing day were eligible for participation. In half the stores, selected at random by us (intervention stores), glass breaking equipment was shut down between visits, although other recycling activities continued, with bottles being collected and stored, unbroken, in the same bins as used for broken glass. Only the investigators knew the identity of stores chosen for the study prior to the start of testing. Sampling days were selected at random and store managers received only 12 hours' advance notice of testing.

A total of 226 employees participated (86\% participation)144 during the first visit and 82 during the second visit (with 44 having repeat testing), thus generating 270 person-visits. Written, informed consent was obtained from all participants, and the UBC research ethics board approved the protocol in advance. No internal control group was included; however, results for chronic symptoms were compared to an external control group of government employees (passenger service workers on coastal ferries) previously studied by us using the identical chronic symptom questionnaire.

\section{Exposure monitoring}

We conducted full shift personal monitoring for each participant on each visit, for IPM and endotoxin, using an IPM sampler (JS Holdings, Hertfordshire) operating at $2 \mathrm{l} / \mathrm{min}$. Concentration was determined by gravimetric analysis. Filters were analysed for endotoxin using a recent improvement to the Limulus amoebocyte lysate assay. ${ }^{3}$ Stationary samplers were also set up outdoors on each visit, in the loading area away from local exhaust outlets. The average sampling time was 5.7 hours. Bulk samples of dust from the surface of glass bins were examined qualitatively by light microscopy.

We also conducted five minute area sampling for viable airborne mesophilic fungi (optimal growth temperature 20$30^{\circ} \mathrm{C}$ ) using Anderson N-6 sampling heads (at $28 \mathrm{l} / \mathrm{min}$ ) and 


\section{Main messages}

- Small scale glass bottle recycling in retail outlets can lead to airborne fungal and particulate matter exposures sufficient to elicit acute and chronic symptoms among employees in these locations.

- Fungal exposures associated with recycling of mould contaminated bottles may lead to chest symptoms.

- Inhalable particulate matter exposures in these setting may contribute to upper airway symptoms.

- High psychosocial job strain (high demand with low control) in these settings may also contribute to symptoms such as headache, nausea, and fatigue.

- Investigations of indoor air quality and exposures in these settings should take into account that different environmental contaminants and stressors may be responsible for different aspects of the overall morbidity experienced by employees.

malt extract agar, at standard locations in each store on each visit: near the glass breaking machine-when operating and not, elsewhere in the warehouse area, at the receiving counter for empty bottles, at the cashier station, and at two outdoor locations. Samples were incubated for seven days at room temperature, and visual counts of colonies and qualitative assessment of the main fungal species present made.

At each visit, an occupational hygienist recorded site specific factors, including staffing levels, ambient conditions, store activities and layout, ventilation, type and duration of glass breaking activities, and volume of bottles handled.

\section{Symptom assessment}

A trained interviewer administered a modified American Thoracic Society questionnaire to each employee, ${ }^{4}$ enquiring about chronic symptoms, job history, and psychosocial aspects of work. ${ }^{5}$ Participants also completed a short questionnaire about the presence, frequency, and severity of symptoms in the past week (acute symptoms), and about specific tasks that day. To limit reporting bias, no mention of work aggravation of symptoms was included in the acute symptoms questionnaire.

Work related chronic symptoms were defined as those not present prior to starting work in the current job, and which improved on holidays or weekends, or were aggravated by

\section{Policy implications}

- Product stewardship programmes that involve glass bottle recycling should be designed to ensure that employee exposures to airborne bioaerosols and particulate matter generated from the recycling process are minimised.

- Glass bottle recycling programmes should include a mechanism for ensuring that mould contaminated bottles are either refused, or are handled in such a way that fungal material is not disseminated into workplace air.

workplace exposures. Acute symptoms were recorded as present only if the symptom occurred more than once during the previous week and with more than minimal severity. Three acute symptom complexes were identified: upper airway irritation (two or more of irritated nose, throat, voice, or taste disturbances), chest symptoms (two or more of cough, wheezing, chest tightness, or breathlessness), and somatic symptoms (two or more of fever, headache, dizziness, tiredness, or nausea).

\section{Data analysis}

Data were analysed using SAS, version 8.1 (SAS Institute, Cary, NC).

\section{Exposure}

Exposure data were log transformed for analysis. We used analysis of variance and $\chi^{2}$ analysis to compare work practices and exposures in intervention and non-intervention stores on each visit (using all 270 samples for analyses of personal environmental samples). We used linear regression to investigate store environment factors related to pollutant levels using modelling strategies described previously. ${ }^{6}$ For personal samples, the dependent variables were either IPM concentration or endotoxin concentration. For viable fungal counts (area samples), three dependent variables were used (in separate models): the mean of all samples taken in each store on each visit, the highest sample taken in each store on each visit, and the mean of all samples from the warehouse and bottle return area of each store on each visit. Independent variables included ambient conditions (indoor and outdoor temperature, humidity, water content of air), other indoor and outdoor exposure variables, visit, store factors (layout and size, general and local ventilation, volume

Table 1 Store factors and work practices by intervention group and visit

\begin{tabular}{|c|c|c|c|c|c|c|}
\hline & \multicolumn{3}{|c|}{ No intervention } & \multicolumn{3}{|c|}{ Intervention } \\
\hline & Visit 1 & Visit 2 & $\mathbf{p}^{*}$ & Visit 1 & Visit 2 & $\mathbf{p}^{*}$ \\
\hline Number of stores & 19 & 19 & & 17 & 17 & \\
\hline \multicolumn{7}{|l|}{ Glass breaking machine in use } \\
\hline Rotary type & $74 \%$ & $74 \%$ & & $65 \%$ & 0 & \\
\hline Glass aggregate type & $26 \%$ & $26 \%$ & & $35 \%$ & 0 & \\
\hline Raking today (\% yes) & $74 \%$ & $63 \%$ & 0.5 & $59 \%$ & 0 & \\
\hline Machine jams cleared today (\% yes) & $26 \%$ & $5 \%$ & 0.07 & 0 & 0 & \\
\hline $\begin{array}{l}\text { Visibly contaminated bottles in breaker, or } \\
\text { broken manually (\% yes) }\end{array}$ & $73 \%$ & $46 \%$ & 0.09 & $63 \%$ & $7 \%$ & $<0.001$ \\
\hline Full glass bins stored overnight (\% yes) & $5 \%$ & $16 \%$ & 0.3 & $12 \%$ & $71 \%$ & 0.005 \\
\hline Glass bins covered (\% yes) & $100 \%$ & $95 \%$ & 0.3 & $100 \%$ & $6 \%$ & $<0.001$ \\
\hline Local exhaust (\% yes) & & & 0.4 & & & $<0.001$ \\
\hline On all day & $32 \%$ & $53 \%$ & 0.4 & $35 \%$ & $6 \%$ & $<0.001$ \\
\hline On during/after breaking & $63 \%$ & $42 \%$ & & $59 \%$ & 0 & \\
\hline Used rarely or never & $5 \%$ & $5 \%$ & & $6 \%$ & $94 \%$ & \\
\hline
\end{tabular}




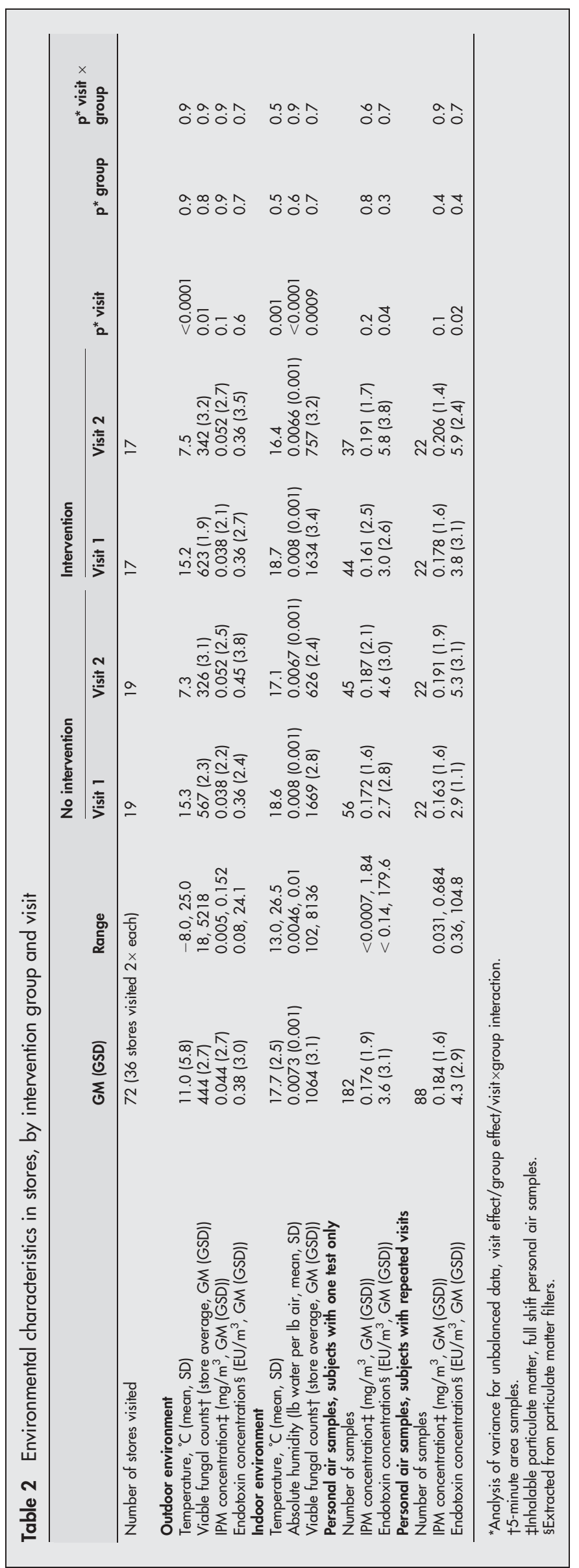




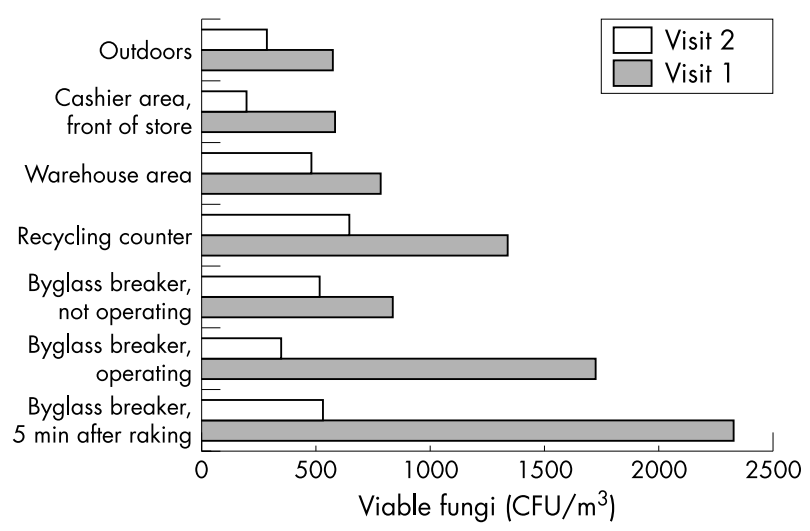

Figure 1 Geometric mean concentration of viable fungi $\left(\mathrm{CFU} / \mathrm{m}^{3}\right)$ from 5 -minute area samples taken at various locations throughout the 35 stores tested ( $n=622$ samples in total). The grey bars represent samples taken during visit 1 (Sept-Dec) and the white bars represents samples taken during visit 2 (Jan-March).

of glass recycled, glass breaking machine type and operation, breaking bottles containing visible mould colonies, and frequency of other exposure reduction techniques such as regular cleaning, covering bins, etc), and (for personal sample models) the proportion of time spent by the employee in specified tasks. Personal exposure models were reanalysed using random effects modelling to take into account the repeated samples.

\section{Exposure-response relations}

We used analysis of variance and $\chi^{2}$ analyses to compare demographic factors, baseline health status, and chronic symptoms among liquor store employees from intervention versus non-intervention stores, and to compare those tested only during visit 1 , those tested only during visit 2 , and those tested twice. We used logistic regression modelling to compare chronic symptoms between liquor store employees and the external control group, and to examine exposureresponse relations between acute symptoms and demographic, personal, and environmental predictors (among liquor store employees only). Potential explanatory factors included: age, gender, race, smoking status and amount, history of asthma and hay fever, psychosocial job strain score, job title and status (regular versus auxiliary), frequency of use of dust mask, proportion of time spent in specified tasks, and all the store and ambient environmental measures described above (including indoor and outdoor pollutant levels). To reduce misclassification from within-person variability in exposure measurements, ${ }^{7}$ individual data for IPM and endotoxin were categorised as "high" or "low" (using median values of $0.2 \mathrm{mg} / \mathrm{m}^{3}$ for IPM and $4 \mathrm{EU} / \mathrm{m}^{3}$ for endotoxin). For viable fungal count data, store average values were used. Factors were tested in multivariable models if they were associated with the outcome in univariate analysis $(p<0.20)$. Highly correlated factors were grouped and analysed separately. Model "fit" was evaluated using adjusted $\mathrm{R}^{2}$ values and likelihood ratios.

\section{RESULTS}

Store characteristics and environmental exposures

Seventeen of the 18 stores in the intervention group complied with the request to shut down the glass breaking machines for the month. Comparison of these stores to those in the non-intervention group showed no significant differences with respect to number of employees, store size, volume of business, work practices of employees, visible crowding, type of glass breaking machine, use of local exhaust ventilation,

Table 3 Environmental, store, machine, and task factors associated with airborne pollutants*

\begin{tabular}{|c|c|c|c|c|c|c|c|c|c|}
\hline & \multicolumn{3}{|c|}{ IPM $\ln \left(\mathrm{mg} / \mathrm{m}^{3}\right)$} & \multicolumn{3}{|c|}{ Endotoxin $\ln \left(\mathrm{EU} / \mathrm{m}^{3}\right)$} & \multicolumn{3}{|c|}{ Viable fungi $\ln \left(\mathrm{CFU} / \mathrm{m}^{3}\right)$} \\
\hline & Coefficient & $\mathbf{p}$ & Partial $\mathbf{R}^{2}$ & Coefficient & $\mathbf{p}$ & Partial $\mathbf{R}^{2}$ & Coefficient & $\mathrm{p}$ & Partial $\mathrm{R}^{2}$ \\
\hline Intercept & -3.3 & $<0.001$ & & -2.01 & $<0.001$ & & 4.4 & $<0.001$ & \\
\hline \multicolumn{10}{|l|}{ Environmental characteristics } \\
\hline Median income in neighbourhood (\$K) & 0.015 & $<0.001$ & 3.6 & & & & 0.023 & $<0.001$ & 2.4 \\
\hline Outdoor IPM (log, $\mathrm{mg} / \mathrm{m}^{3}$ ) & 0.14 & $<0.001$ & 6.8 & & & & & & \\
\hline $\begin{array}{l}\left.\text { Indoor IPM (log } \mathrm{mg} / \mathrm{m}^{3}\right) \\
\text { Outdoor funqi }\left(\text { log CFU } / \mathrm{m}^{3} \text { ) }\right.\end{array}$ & & & & 0.81 & $<0.001$ & 20.9 & & & \\
\hline $\begin{array}{l}\text { Absolute humidity indoors } \\
\text { (lb water per } \mathrm{lb} \text { air } \times 100 \text { ) }\end{array}$ & & & & -1.69 & $<0.001$ & 3.8 & $\begin{array}{l}0.21 \\
1.38\end{array}$ & $\begin{array}{r}<0.001 \\
0.003\end{array}$ & $\begin{array}{l}2.5 \\
4.5\end{array}$ \\
\hline \multicolumn{10}{|l|}{ Store characteristics } \\
\hline Store situated below grade (yes/no) & & & & 0.82 & $<0.01$ & 2.4 & 0.77 & 0.002 & 3.2 \\
\hline Crowded warehouse (yes/no) & & & & & & & -0.34 & 0.002 & 0.4 \\
\hline Receives empties in bulk (e.g. from bars) (yes/no) & & & & & & & 2.0 & $<0.001$ & 1.9 \\
\hline $\begin{array}{l}\text { No. wine bottles returned, prior month } \\
(<20 \mathrm{~K}(20-40 \mathrm{~K} />40 \mathrm{~K})\end{array}$ & & & & & & & -0.71 & $<0.001$ & 0.1 \\
\hline $\begin{array}{l}(<20 \mathrm{~K} / 20-40 \mathrm{~K} />40 \mathrm{~K}) \\
\text { Machine characteristics }\end{array}$ & & & & & & & & & \\
\hline \multicolumn{10}{|l|}{ Machine characteristics } \\
\hline Hydraulic rotary conveyort & & & & & & & 2.58 & $<0.001$ & 12.5 \\
\hline Rotary conveyort & & & & & & & 0.78 & $<0.001$ & 1.1 \\
\hline Machine steam cleaned, past month (yes/no) & & & & & & & -0.47 & 0.001 & 0.5 \\
\hline Characteristics related to recycling activities & & & & & & & & & \\
\hline Local exhaust always on (yes/no) & -0.14 & 0.06 & 1.1 & & & & & & \\
\hline Visually mouldy bottles being broken (yes/no) & & & & & & & 1.09 & $<0.001$ & 21.3 \\
\hline Glass bins covered (yes/no) & & & & & & & -0.68 & 0.005 & 0.7 \\
\hline \multicolumn{10}{|l|}{ Employee tasks } \\
\hline Stocking shelves (\% of day) & 0.010 & $<0.001$ & 3.1 & & & & & & \\
\hline $\begin{array}{l}\text { Handling pallets/boxes in warehouse } \\
\text { (\% of day) }\end{array}$ & 0.008 & $<0.001$ & 5.0 & 0.006 & 0.07 & 1.1 & & & \\
\hline $\begin{array}{l}\text { Empties/breaking (\% of day) } \\
\text { Smoker (yes } / \mathrm{no} \text { ) }\end{array}$ & 0.006 & $<0.05$ & 1.4 & 0.010 & 0.02 & 1.6 & & & \\
\hline Smoker (yes/no) & & & & 0.28 & 0.03 & 1.3 & & & \\
\hline Model R† & & & 0.21 & & & 0.31 & & & 0.52 \\
\hline
\end{tabular}

*Coefficients, p values, partial correlation coefficients from multiple linear regression models including each of the variables for which coefficient values are shown. †These two types of machines are the only types that required manual raking of the broken glass cone. 
Table 4 Characteristics of participants compared to an external control working population

\begin{tabular}{|c|c|c|c|c|c|c|}
\hline & \multicolumn{3}{|c|}{ Liquor store employees } & \multirow[b]{2}{*}{$\mathbf{p}^{*}$} & \multirow{2}{*}{$\begin{array}{l}\text { External control } \\
\text { group }\end{array}$} & \multirow[b]{2}{*}{ p† } \\
\hline & Tested V1 \& V2 & Tested V1 only & Tested V2 only & & & \\
\hline Number & 44 & 100 & 82 & & 122 & \\
\hline \multicolumn{7}{|l|}{ Smoking status } \\
\hline Never & $23 \%$ & $43 \%$ & $29 \%$ & & $35 \%$ & \\
\hline Former & $43 \%$ & $29 \%$ & $39 \%$ & 0.1 & $38 \%$ & 0.7 \\
\hline Current & $34 \%$ & $28 \%$ & $32 \%$ & & $27 \%$ & \\
\hline Age, years (mean, SD) & $45.5(8.4)$ & $41.2(8.9)$ & $44.0(9.0)$ & 0.04 & $47.1(11.3)$ & $<0.01$ \\
\hline Gender: \% male & $43 \%$ & $60 \%$ & $46 \%$ & 0.08 & $67 \%$ & $<0.01$ \\
\hline Ethnicity: \% Caucasian & $98 \%$ & $88 \%$ & $92 \%$ & 0.2 & $86 \%$ & 0.07 \\
\hline \multicolumn{7}{|l|}{ Job title } \\
\hline Manager & $27 \%$ & $14 \%$ & $17 \%$ & 0.001 & NA & $<0.01$ \\
\hline Regular clerk & $59 \%$ & $39 \%$ & $49 \%$ & & & \\
\hline Auxiliary clerk $\ddagger$ & $14 \%$ & $47 \%$ & $34 \%$ & & & \\
\hline Asthma (diagnosed, ever) & $7 \%$ & $9 \%$ & $21 \%$ & 0.03 & $7 \%$ & 0.9 \\
\hline Hay fever (diagnosed, ever) & $16 \%$ & $18 \%$ & $16 \%$ & 0.9 & $11 \%$ & 0.1 \\
\hline Psychosocial job strain score§ (mean, SD) & $0.83(0.19)$ & $0.88(0.24)$ & $0.83(0.22)$ & 0.3 & $0.68(0.14)$ & $<0.01$ \\
\hline
\end{tabular}

indoor temperature or humidity, or the median income in the neighbourhood (data not shown). As expected, the intervention resulted in significant changes in work practices (table 1). In intervention stores, raking of the broken glass was no longer required but glass bins were much more likely to remain uncovered and to be stored overnight in the store. In some intervention stores, although the glass breaking machinery was not used, bottles were thrown forcibly into the bins and broken manually.

Ambient environmental characteristics in the stores varied significantly between visits (table 2), but did not differ in relation to intervention group status, or to the intervention itself (interaction of group and visit). Outdoor and indoor temperature and absolute humidity decreased significantly between visits in both groups of stores (visit 1 was mainly in the autumn; visit 2 in the winter). IPM concentrations were slightly higher, endotoxin concentrations significantly higher, and fungal counts significantly lower at visit 2 compared to visit 1 in both groups of stores. Viable fungi levels varied according to location in the store (fig 1). During visit 1 , the highest counts were associated with glass breaking machines; during visit 2, counts were lower at all locations, with the highest counts seen at the recycling counter. This is likely related to the fact that between visits the glass bins were moved away from the glass breakers and closer to the recycling counter in stores not using the glass breaking machines. The mean endotoxin content of the IPM samples (that is, amount of endotoxin per mg of dust) was $27.0 \mathrm{EU} / \mathrm{mg}$ (range 7.9-39.7 EU/mg). IPM and endotoxin concentrations were correlated (Pearson's $\mathrm{R}^{2}=0.46$, $\mathrm{p}<0.001, \log$ transformed values), but neither IPM nor endotoxin concentrations were correlated with fungal counts.

Qualitative inspection of particulate matter bulk samples via light microscopy revealed the majority of structures

Table 5 Chronic symptom prevalence rates, liquor store employees compared to an external control population

\begin{tabular}{|c|c|c|c|c|c|c|c|}
\hline \multirow[b]{2}{*}{ Symptom } & \multicolumn{3}{|c|}{ Liquor store group } & \multirow[b]{2}{*}{$\mathbf{p}^{*}$} & \multirow[b]{2}{*}{$\begin{array}{l}\text { Control } \\
\text { group }\end{array}$} & \multirow[b]{2}{*}{ pt } & \multirow[b]{2}{*}{ Odds ratio $\ddagger(95 \% \mathrm{Cl})$} \\
\hline & $\begin{array}{l}\text { Tested } \\
\text { V1 \& V2 }\end{array}$ & $\begin{array}{l}\text { Tested V1 } \\
\text { only }\end{array}$ & $\begin{array}{l}\text { Tested V2 } \\
\text { only }\end{array}$ & & & & \\
\hline Number & 44 & 100 & 82 & & 122 & & \\
\hline \multicolumn{8}{|l|}{ Cough } \\
\hline Usual cough & $9 \%$ & $12 \%$ & $18 \%$ & 0.3 & $11 \%$ & 0.6 & $1.2(0.6$ to 2.4$)$ \\
\hline Work related cough & $7 \%$ & $5 \%$ & $5 \%$ & 0.8 & $7 \%$ & 0.4 & $0.7(2.3$ to 1.8$)$ \\
\hline \multicolumn{8}{|l|}{ Phlegm } \\
\hline Usual phlegm & $2 \%$ & $12 \%$ & $11 \%$ & 0.2 & $22 \%$ & $<0.01$ & $0.4(0.2$ to 0.7$)$ \\
\hline Work related phlegm & 0 & $2 \%$ & $2 \%$ & 0.6 & $5 \%$ & 0.1 & $0.4(0.1$ to 1.4$)$ \\
\hline \multicolumn{8}{|l|}{ Wheeze } \\
\hline Occasional, apart from colds & $14 \%$ & $20 \%$ & $26 \%$ & 0.3 & $21 \%$ & 0.9 & $0.7(0.4$ to 1.3$)$ \\
\hline Work related wheeze & $5 \%$ & $8 \%$ & $18 \%$ & 0.03 & $8 \%$ & 0.4 & $1.3(0.6$ to 2.9$)$ \\
\hline \multicolumn{8}{|l|}{ Chest tightness } \\
\hline Episodes or attacks & $27 \%$ & $22 \%$ & $41 \%$ & 0.02 & $17 \%$ & $<0.01$ & 1.8 (1.1 to 3.3$)$ \\
\hline Work related chest tightness & $5 \%$ & $4 \%$ & $15 \%$ & 0.02 & $2 \%$ & 0.02 & $4.8(1.1$ to 21.5$)$ \\
\hline \multicolumn{8}{|l|}{ Dyspnoea } \\
\hline Hurrying on the level & $18 \%$ & $16 \%$ & $17 \%$ & 0.9 & $22 \%$ & 0.2 & $0.8(0.4$ to 1.4$)$ \\
\hline \multicolumn{8}{|l|}{ Nasal symptoms } \\
\hline Sneezing, itching, running & $57 \%$ & $61 \%$ & $63 \%$ & 0.8 & $49 \%$ & 0.03 & $1.4(0.9$ to 2.2$)$ \\
\hline Work related nasal symptoms & $30 \%$ & $27 \%$ & $35 \%$ & 0.5 & $13 \%$ & $<0.01$ & $3.1(1.6$ to 5.8$)$ \\
\hline \multicolumn{8}{|l|}{ Eye symptoms } \\
\hline Burning, itching, watering & $9 \%$ & $20 \%$ & $13 \%$ & 0.2 & $19 \%$ & 0.4 & $0.7(0.4$ to 1.3$)$ \\
\hline Work related eye symptoms & $2 \%$ & $9 \%$ & $9 \%$ & 0.3 & $3 \%$ & 0.1 & $2.5(0.8$ to 8.9$)$ \\
\hline Asthma, diagnosed past 3 years & 0 & 0 & $5 \%$ & 0.03 & $3 \%$ & 0.9 & $1.2(0.2$ to 7.0$)$ \\
\hline
\end{tabular}


Table 6 Risk factors for acute symptom complexes*: odds ratios $\uparrow(95 \% \mathrm{Cl})$ from multivariable logistic regression models (liquor store employees only)

\begin{tabular}{|c|c|c|c|}
\hline & $\begin{array}{l}\text { Upper airway } \\
\text { symptoms }\end{array}$ & Chest symptoms & Somatic symptoms \\
\hline $\mathrm{n}(\%)$ with symptom $\ddagger$ & $47(20.8 \%)$ & $35(15.5 \%)$ & $25(11.1 \%)$ \\
\hline Visit & $1.1(0.4$ to 2.5$)$ & $1.6(0.6$ to 4.1$)$ & $3.7(1.2$ to 11.6$)$ \\
\hline Personal inhalable particulate matter $>0.20 \mathrm{mg} / \mathrm{m}^{3}$ (yes $/ \mathrm{no}$ ) & $2.3(1.1$ to 4.9$)$ & $1.8(0.7$ to 4.3$)$ & $0.9(0.3$ to 2.4$)$ \\
\hline Personal endotoxin $>4 \mathrm{EU} / \mathrm{m}^{3}$ (yes $/ \mathrm{no}$ ) & $1.6(0.7$ to 3.2$)$ & $1.5(0.6$ to 4.7$)$ & $1.6(0.6$ to 4.4$)$ \\
\hline Store average indoor fungal count (CFU $/ \mathrm{m}^{3}$ ) & $1.0(0.9$ to 1.1$)$ & $1.0(0.9$ to 1.0$)$ & $1.0(0.9$ to 1.0$)$ \\
\hline Visibly mouldy bottles broken on study day (yes/no) & $1.5(0.6$ to 3.6$)$ & 3.1 (1.2 to 8.2$)$ & $1.0(0.3$ to 3.2$)$ \\
\hline Glass breaker operating, past month (yes/no) & $1.7(0.6$ to 5.2$)$ & $2.4(0.6$ to 9.4$)$ & $2.1(0.6$ to 7.8$)$ \\
\hline High job strain score (yes/no) & $1.6(0.8$ to 3.4$)$ & $1.0(0.4$ to 2.6$)$ & $3.1(1.2$ to 7.8$)$ \\
\hline History of asthma (yes/no) & $1.4(0.5$ to 3.6$)$ & 4.5 (1.7 to 11.7$)$ & $0.7(0.2$ to 2.8$)$ \\
\hline
\end{tabular}

*Moderate or severe symptoms in previous week, defined as: upper airway: two or more of: irritated nose, throat, voice, or taste disturbances; chest: two or more of: cough, wheezing, chest tightness, breathlessness; somatic: two or more of: fever, headache, dizziness, tiredness, nausea.

†Odds ratios from logistic regression models including all the variables listed in the same model; bold indicates odds ratios greater than 1 at $p<0.05$.

$\ddagger$ Total $n=226$ (acute symptom data reported for first testing occasion only for those with repeated data).

consistent with finely broken glass particles. Qualitative identification of fungal plates revealed that almost all outdoor samples (96\%) reflected the typical "outdoor" species mix for our region (Cladosporium sp, sterile mycelium, yeast). The majority of samples taken indoors $(>80 \%$, appeared to reflect other sources, not simply a transfer of "outdoor" spores into the building. The predominant fungal group found indoors was Penicillium spp (predominant on almost all plates). Other species included Botrytis $(6.4 \%$ of samples positive), Aspergillus spp (1.7\% of samples positive), and Rhizopus (1.7\% of samples positive).

\section{Store environment and work factors associated with exposure levels}

The main contributing factors associated with personal IPM were outdoor IPM and increased time spent stocking shelves and working in the recycling area of the store (table 3). The main factors in the model for personal endotoxin were personal IPM and increased time in the recycling areas. The intervention (stopping glass breaking machines) appeared to have no impact on airborne IPM or endotoxin. In the model for store average viable fungal concentrations, the most important factor was the breaking of visually mouldy bottles (either by machine or manually). Other factors contributing to increased fungal counts were uncovered glass bins in the store and the use of rotary glass breaking machines (the only machines for which raking of the broken glass cone was required). Results from models examining peak fungal counts or average counts in the recycling area only were almost identical to these. Random effects models incorporating the 44 repeated samples from employees tested twice indicated similar results.

\section{Health assessment-participants}

Table 4 shows demographic characteristics of the participants and the external control group. There were no significant differences among employees of the intervention versus nonintervention stores (not shown), but there were significant differences among employees tested at visit 1 only $(n=100)$, those tested at visit 2 only $(\mathrm{n}=82)$, or those tested at both visits $(n=44)$. Those tested twice had more job seniority and were more likely to be managers; those tested only at visit 2 were significantly more likely to have a history of asthma. There were also significant differences comparing all liquor store employees to the external control group, with the control group being slightly older and having more male employees. Smoking status did not differ across groups.

Chronic symptoms versus external control population Table 5 shows prevalence rates for chronic and work related symptoms among liquor store employees (by visit) and the external control group. Consistent with differences in asthma prevalence among the liquor store groups, work related wheeze and chest tightness were more prevalent in those tested at visit 2. Compared to the external control group, liquor store employees had more chest tightness and nasal symptoms (in general and in relation to work), and less phlegm production, even after taking into account differences in age, gender, and history of hay fever and asthma.

\section{Acute symptoms and exposure-response relations}

Because of the significant baseline heterogeneity among participants tested on different visits and changes in environmental conditions by visit, and because results of the exposure analyses revealed no significant impact of the intervention on environmental conditions, analyses of relations between exposures on the study day and acute symptoms were carried out on all participants, using data from the first test only (from either visit 1 or 2 ) for each participant. (Parallel analyses using visit 1 data only showed similar odds ratios although wider confidence intervals.)

None of the acute symptom complexes was associated with gender, age, smoking, or history of hay fever, in univariate analyses. The only significant environmental factor was high versus low IPM exposure associated with increased acute upper airway irritation $(29 \% v 15 \%, \mathrm{p}=0.02)$.

In multivariable analyses, the only factors significantly associated with any acute symptom complex were visit, airborne exposures, breaking visibly mouldy bottles, psychosocial job strain score, and history of asthma, although not all were significant in all models. To allow direct comparison the effects of these factors on the different symptom complexes, models were constructed including all variables, plus glass breaking machine status (that is, intervention) (table 6). Acute upper airway irritation was significantly associated with increased IPM; acute chest symptoms were significantly associated breaking mouldy bottles in the store (an indirect marker of fungal exposures) and with asthma history; and acute somatic symptoms were significantly associated with increased psychosocial job strain (ratio of perceived job demands to control over tasks) and visit. The analyses were repeated using log transformed values for IPM and endotoxin rather than categorical values, using store average values in place of individual values, and substituting peak fungal levels for averages.

\section{DISCUSSION}

Our results suggest that health complaints associated with the introduction of recycling in this environment were best explained when multiple exposures were considered together. Acute upper airway irritation was linked to airborne 
particulate matter, acute chest symptoms were indirectly linked to the fungal exposures associated with breaking mouldy bottles, and acute somatic symptoms were more strongly linked to psychosocial aspects of the work. This suggests that intervening in only one aspect of the recycling programme was not effective in sufficiently altering the environment to reduce airborne contaminants or symptoms.

The results showing increased chronic nasal symptoms and chest tightness are consistent with those for acute symptoms. This is not surprising, as the recycling programme had been in place in these stores for almost two years prior to our investigation. After our results were reported to stakeholders, glass breaking was discontinued and a programme introduced encouraging customers to wash bottles prior to returning them (and permitting employees to refuse visibly contaminated bottles). Anecdotal reports indicate that symptoms have decreased since. Given that the intervention tested here did not appear to affect airborne concentrations and that acute symptoms were more closely associated with breaking visibly mouldy bottles than with glass breaker operation, it is more likely that the second change was the critical one. To confirm this, one would need a second controlled study.

The association between mucous membrane irritation and particulate matter is biologically plausible but, to our knowledge, has not been reported previously. Our findings are consistent with reports of similar symptoms among persons exposed to fibrous glass. ${ }^{8}$ We were unable to find any published references to the health effects of fine glass particles. Crushed glass from recycling is used in the manufacture of abrasives and construction products, and investigations have evaluated toxic metal constituents of glass, but have not commented on potential irritant effects of particles. ${ }^{910}$ Anecdotal information from internet sites ${ }^{11-13}$ suggests neighbourhood concerns about "glass dust" and respiratory problems from glass crushing facilities in three US states; however, no scientific evaluation of these complaints appears available.

Recycling of organic materials has been associated with bioaerosol exposures (including endotoxin and fungi) and adverse respiratory outcomes. ${ }^{14}{ }^{15}$ We found no association between airborne endotoxin and symptoms in this study. In contrast to organic waste recycling, endotoxin levels in this study were low, but levels were consistent with those found in samples of house dust from residences. ${ }^{16}{ }^{17}$ Endotoxin levels were correlated with IPM concentrations, but over 75\% of the variability in endotoxin remained unexplained. ${ }^{18}$

Our results regarding airborne mould are consistent with other studies. The most important factor was a point source (mouldy bottles) and an efficient method for distributing spores (breaking bottles, either mechanically or manually). Other studies have shown visible mould in homes to be an important determinant of viable fungal counts in air,; ${ }^{19}$ however, one study found the reverse and the authors speculated this might have been due to ingress of outdoor fungi. ${ }^{21}$ One study that did find an association between visible mould and viable mould in air reported no correlation between visible mould and total airborne fungal biomass (ergosterol)..$^{20}$

We also found that acute chest symptoms were associated with breaking visibly mouldy bottles, but not with measurements of viable fungi. A similar finding was seen among asthmatics sensitive to mould, in whom peak flow variability was associated with variations in visible mould over one year, but not with total fungi or ergosterol. ${ }^{22}$ Another study of Australian households (half with an asthmatic child), found an association between cough and wheeze and viable indoor Cladosporium spores, but not with mean total spore concentrations. ${ }^{21}$ These findings emphasise that further work is needed to develop methods to characterise indoor exposures to airborne and surface mould when studying respiratory health. However, our findings also underscore the importance of considering the role of other environmental agents in promoting symptoms when studying indoor environments.

There are limitations to our study. Because of scheduling changes, most participants were not present at both visits, making it impossible to analyse changes in symptoms across visits. Furthermore, visit related differences in environmental conditions and baseline characteristics of participants limited analysis of symptoms in relation to the intervention. Some environmental changes were likely related to seasonal effects as well as to changes in work practices in all stores. To overcome these limitations, we took advantage of the increased variability in environmental exposures generated by pooling data across visits and analysed exposure-response relations in pooled data while taking into account "visit" as a marker of seasonal differences. This approach was supported by the non-impact of the intervention on environmental conditions and the finding that results did not differ appreciably when only visit 1 data were used.

Another limitation is that the health assessment was based on self-report of symptoms and neither participants nor interviewers were blinded to the intervention status. However, it is unlikely that employees could have altered their reports in association with exposure levels, as these differences were too subtle to detect "visibly" (even for the experienced hygienist carrying out the fieldwork). Furthermore, the association of symptoms with visible mould exposure, although perhaps obvious in retrospect, was not a source of employee concern during the study. Rather, employee concerns had centred on "glass dust" (hence the original intervention). Respondent bias in comparisons to the control population is also possible. However, the controls were studied originally as a result of employee concerns about their work environment, ${ }^{*}$ reducing the likelihood of significant bias from this source.

In 1995, in a review of occupational health problems from recycling domestic waste, Poulsen et al noted there are a "multitude of health problems among workers" handling unseparated domestic waste, compost, and recycling paper products; but no studies examining health problems or exposures associated with recycling of glass products. ${ }^{23}$ Our study provides the first direct evidence of potential health effects of glass bottle recycling, and indicates that glass bottle recycling accompanied by glass breaking may give rise to particle and fungal exposures sufficient to elicit upper airway and chest symptoms among employees.

\section{ACKNOWLEDGEMENTS}

We thank the management and staff of the BC Liquor Distribution Branch stores who participated in this study and Sonia $\mathrm{Na}$, who carried out the fieldwork.

\section{Authors' affiliations}

S M Kennedy, R Copes, K H Bartlett, M Brauer, School of Occupational and Environmental Hygiene, University of British Columbia, Vancouver BC, Canada

Supported in part by a grant from the Workers' Compensation Board of British Columbia

* The control population was studied in 1999 because of employee concern about past asbestos exposure on the ferries. Results (see: www. soeh.ubc.ca/research/index.html) showed asbestos related health outcomes limited to employees working in the engine room or in maintenance jobs, and not among those working in the passenger service areas. The control population used here was limited to passenger service crew. 


\section{REFERENCES}

1 Sigsgaard T, Malmros P, Nersting L, et al. Respiratory disorders and atopy in Danish refuse workers. Am J Respir Crit Care Med 1994; 149:1407-12.

2 Sigsgaard T, Abel A, Donbaek L, et al. Lung function changes among recycling workers exposed to organic dust. Am J Ind Med 1994;25:69-72.

3 Dennekamp M, Demers P, Bartlett K, et al. Endotoxin exposure among softwood lumber mill workers in the Canadian province of British Columbia. Ann Agric Environ Med 1999;6:141-6.

4 Ferris BG. Epidemiology standardization project (American Thoracic Society). Am Rev Respir Dis 1978;118:1-120.

5 Ostry AS, Marion SA, Demers PA, et al. Measuring psychosocial job strain with the job content questionnaire using experienced job evaluators. Am J Ind Med 2001;39:397-401.

6 Teschke K, Demers PA, Davies HW, et al. Determinants of exposure to inhalable particulate, wood dust, resin acids, and monoterpenes in a lumber mill environment. Ann Occup Hyg 1999;43:247-55.

7 Anon. A comparison of exposure grouping methods to reduce attenuation in exposure-response: an analysis of wood dust exposure and lung function. Goteberg, Sweden: Exposure Assessment in Epidemiology and Practice, 2001.

8 Hunting KL, Welch LS. Occupational exposure to dust and lung disease among sheet metal workers. Br J Ind Med 1993;50:432-42.

9 Obery AM, Landis WG. Assessment of environmental toxicity from spent recycled glass abrasives. Seattle, WA: Institute of Environmental Toxicology and Chemistry, 1999:1-32.

10 KTA-Tator I. Evaluation of substitute materials for silica sand abrasive blasting Contract No. 200-95-2946. Dept of Health and Human Services, National Institute for Occupational Safety and Health, 1999.

11 Bacon D. Recycling-not so green to its neighbors. David Bacon Stories and Photographs. 10-9-1997. http://dbacon.igc.org/Imgrants/09recycl.html. 12 June 2003.
12 US Environmental Protection Agency. Region 5-Office of Regional Counsel. Enforcement Action Database, Fiscal Year 1999. 8-27-1999. 6-12-2002. http://www.epa.gov/region5/orc/enfactions99/week-0899.htm. 12 June 2003.

13 Martineau K. Glass-recycling plant target of complaints. Times Union 2000 Jan 8. http://capital.net/ force/tul8_00.htm. 12 June 2003.

14 Douwes J, Wouters I, Dubbeld H, et al. Upper airway inflammation assessed by nasal lavage in compost workers: a relation with bio-aerosol exposure. Am J Ind Med 2000;37:459-68.

15 Bunger J, Antlauf-Lammers M, Schulz TG, et al. Health complaints and immunological markers of exposure to bioaerosols among biowaste collectors and compost workers. Occup Environ Med 2000;57:458-64.

16 Douwes J, Zuidhof A, Doekes G, et al. ( $1 \rightarrow 3$ )-beta-D-glucan and endotoxin in house dust and peak flow variability in children. Am J Respir Crit Care Med 2000;162:1348-54

17 Wickens K, Douwes J, Siebers R, et al. Determinants of endotoxin levels in carpets in New Zealand homes. Indoor Air 2003;13:128-35.

18 Park JH, Gold DR, Spiegelman DL, et al. House dust endotoxin and wheeze in the first year of life. Am J Respir Crit Care Med 2001;163:322-8.

19 Dharmage S, Bailey M, Raven J, et al. Prevalence and residential determinants of fungi within homes in Melbourne, Australia. Clin Exp Allergy 1999;29:1481-9.

20 Dales RE, Miller D, McMullen E. Indoor air quality and health: validity and determinants of reported home dampness and moulds. Int J Epidemiol 1997;26:120-5.

21 Garrett MH, Rayment PR, Hooper MA, et al. Indoor airborne fungal spores, house dampness and associations with environmental factors and respiratory health in children. Clin Exp Allergy 1998;28:459-67.

22 Dharmage S, Bailey M, Raven J, et al. Mouldy houses influence symptoms of asthma among atopic individuals. Clin Exp Allergy 2002;32:714-20.

23 Poulsen OM, Breum NO, Ebbehoj N, et al. Sorting and recycling of domestic waste. Review of occupational health problems and their possible causes. Sci Total Environ 1995; 168:33-56. 